\title{
FRAY HERNANDO DE TALAVERA Y EL TEATRO: EL OBISPILLO
}

Jose Fradejas

Fray Hernando no ve con buenos ojos las diversiones profanas; considera pecaminosas las risas más o menos desmesuradas y rechaza a los que están en la iglesia.

jugando, saltando, cantando, bailando, danzando...

Item haciendo en ellas zaharrones y otros deshonestas representaciones.

A quienes profesan estas infames artes

truhanes y semejantes oficiales, que raramente usan de su oficio sin pecar, no se debe ligeramente dar

la sagrada Eucaristía (1).

Es posible y parece lógico que, cuando Hernando Pérez era niño de 6 u 8 años, asistiera a alguna representación religiosa, especialmente de la Pasión. Nuestra afirmación se basa en que en esas fechas coincidían en Talavera de la Reina un seise y educando de la «colegial de Santa María la Mayor» de Talavera que un día será Arzobispo de Granada y Alfonso Martínez de Toledo que dice en su libro:

Representación de la Pasión fazen al Carmen (2). 
Martínez de Toledo, Arcipreste de Talavera, escribe su libro en 1438, pero sus aficiones teatrales siguieron muchos años; sabemos que intervino en

1456 en la representaçiones que fizo [en Toledo] en la fiesta del Corpus.

1458 en la representaçión de los pastores de la fiesta de Navidad.

1461 en la representaçión de Nuestra Señora de la Asumpción.

Si el joven Hemando se emociono con aquella representación, desde luego le marc6 para toda su vida, pues, cuando en 1486 escribe la regla para las monjas Bernardas de Ávila, les manifiesta que

comulgando muy devotamente el jueves de la Santa Cena, debíades REPRESENTAR, santificar y honrrar la institución de aqueste santísimo sacramento, que fue instituido en ella (3).

En la Breve summa, quizá de Jerónimo de Madrid, abad de Santa Fe, se cuenta

Desta manera atrahía el varón de Dios tanta gente a los maitines como a la missa; otras vezes hazía hazer algunas REPRESENTAÇIONES tan devotas que eran más duros que piedras los que no echaban lágrimas de devoción (4).

Es muy verosímil que se refiriera aquí a una fiesta religiosa típicamente escolar, frecuente en las escuelas catedralicias y monásticas medievales, de las que dice de la Rosa que

es una de las antiguas representaciones religiosas, de cuyo género místico tanto gustara la piedad de nuestros mayores (5).

Nos estamos refiriendo al Obispillo.

Precisamente el ms. 11050 de la Biblioteca Nacional de Madrid, en su primera parte, contiene una Biografia de fray Hemando, y en el Capítulo X, que se titula «Del colegio que hizo de clérigos», al margen hay una anotación que dice Obispillo y en el

Sumario de la vida del primer arçobispo de Granada, don fray Hernando de Talavera, y de su gloriosa muerte. Évora, Andrés de Burgos, XX de Octubre de 1557, en el capítulo XI, hay un titulillo a mediados de êl: Del Obispillo (6). 
Estas dos biografías según el P. Félix García Olmedo son dos versiones, segunda y tercera, de una escrita en 1507 por Alonso Fernández de Madrid, Arcediano de Alcor, familiar de fray Hernando en Granada. La segunda debió escribirse hacia 1530, a petición de don Luis Vaca de Guzmán y la tercera versión, retocada ora por él o por algún otro, se publicó dedicada al Infante Cardenal don Enrique de Portugal.

De la primera versión no tenemos noticias, se deduce de la segunda, que permaneció inédita hasta 1931 ; por tanto, damos a conocer la más antigua versión impresa, la de 1557 , que dice así.

\section{Del Obispillo}

No dexare de contar una cosa aunque algunos la juzgaban por redrcula y liviana por no saber: y ella era en sí harto macica y de gran representación y deuoción. Acostumbrábase antiguamente en las yglesias cathedrales, que el dia del Seĥor Sant Nicolás elegian de entre los moços de coro un obispillo, cuya dignidad dura hasta el día de los innocentes, que es su propria fiesta. Y entonces se mudan los oficios de los mayores en los menores: y estos mandan y los otros obedecen y son servidos y acatados aquel día los que todo el af́o andan subjectos sirviendo. Pues como el Arçobispo era tan amigo destas representaciones y cerimonias de la yglesia, tomaba la cosa tan de veras como a la verdad ella lo debía ser antes quel demonio mezclasse en ello otras vanidades desonestas, que en algunas partes se hazen. Llegada pues la vigilia de Sant Nicolás, el se venía a la yglesia y cabildo, donde haziendo juntar aquellos veinte y cinco collegiales fazfa una muy bien ordenada habla en favor de la honestidad y delos exercicios ecclesiásticos y dándoles a entender qué tal abía de ser el perlado y que cosas abfan de concurrir en el; y mostrándoles la razón de aquella fiesta, y lo que Sant Nicolas abra merecido por donde le abian elegido por Obispo de la yglesia de Dios. E luego tras esto encargaba la conciencia a todos los del cabildo, y al rector del collegio, y a los otros que conocian aquellos mancebos y les conjuraba qual de aquellos tenía más abilidad para aquella dignidad: assí en letras como en humildad y buena conversación: en fin él hazia todo aquel escrutinio y diligencia para hazer un obispillo de veinte días, quanta hiziera para hazer un obispo perpetuo. $Y$ tomando el parescer de todos elegia por obispillo al que mejor lo merecfa: y era aquello tenido en harto: porque demás del favor y buena reputación que aquel cobraba, aun le venía más provecho temporal, que para ayuda a su vestuario y otras cosillas necessarias estaba assf ordenado, que dende el día de Sant Nicolás hasta el día de los innocentes ganaba el Obispillo las distribuciones del coro como un racionero: y se sentaba junto con ellos en su silla y orden: y no sé si después se ha esto mudado. Era una cosa que de muchos clérigos se debiera ir a ver el día 
de los innocentes, el auctoridad con que al obispillo llevaban desde el collegio al coro vestido de pontifical: llevándole la falda el mismo Arçobispo con aquella humildad que el otro se la llevara a él y sirviendo las dignidades y canónigos oficios delos mosos y ellos con mucha autoridad muy bien ataviados de ropas y sobrepellizes acompañando a su perlado: y todo esto con tanta orden y silencio como quando el mismo Arçobispo celebraba: ver la alegría con que él servía aquel día en el coro poniendo o quitando los libros que eran harto grandes: $y$ bolviendo las hojas guardando el verso siempre, en pie cabe el facistorio y sin bonete y despues con que humildad y subjeción trataba y servia al tan duro que no derramasse muchas lágrimas de devoción y en verdad que en el tiempo que yo lo vi ninguna representación ni cerimonia ni oficio se fazía en la yglesia que no fuesse muy devota pero esta a mi ver era una cosa de gran edificación y desde el principio de la elección del Obispillo hasta el fin todo trara doctrina y humildad: disciplina y imitacion. Esto he querido dezir aquí porque vino al proposito y por significar en quantas cosas era señalado este buen perlado: pues aun de las cosas que parecfan baxas y despreciadas sacaba fructo para todos según el gusto de cada uno.

Pero analicemos los orígenes y trayectoria de esta festividad escolar. Cuenta Julio Caro Baroja que fray Bartolomé de las Casas no vacilaba en considerar la fiesta del obispillo como un vestigio de las Saturnales (7).

Es el CLXV, Historiadores de Indias, I, NBAE, XIII, Madrid, 1909, pág. 437 a: «De otra manera y más solemne libertad que tenfan en Roma en los días de las fiestas Saturnales o de Saturno, alcanzaban los esclavos o siervos, porque los esclavos se vestían los vestidos de los sef̂ores, y los señores, los vestidos de los esclavos; los esclavos enviaban dinero y presentes a los señores, y los señores a los esclavos. Elegianse aquellos días reyes, y como reyes mandaban, y lo mismo los otros oficios y magistrados, y vestranse de púrpura y grana, y los demás eran vestidos de blanco. El vestigio de esto parece haber quedado entre nosotros los cristianos en la costumbre que hay de hacer los obispillos en las iglesias catedrales por el día de Sant Nicolás...» Poco más adelante (pág. 437, b), al tratar de las estrenas y aguinaldos, dice: $\ll Y$ asi remanece hoy en los días de Navidad hasta la Epifanfa el vestigio y restos de aquellas fiestas entre los cristianos, y hoy que esto escribo, veo las comidas y convites que unos a otros frecuentisimamente se hacen.»

Estos remotos orígenes recibieron un tratamiento cristianizado, como tantas otras festividades, por ejemplificar una sola recordemos la Sanjuanada 
cristiana o Ansara musulmana, de orígenes también paganos pero adaptados a las religiones correspondientes (8).

Consistía lo fundamental de aquella fiesta en que, cantado el versículo Deposuit potentes de sede, correspondiente al cántico Magnificat, en las visperas del día de los Santos Inocentes, uno de los niños de coro, el electo obispillo, vistiendo el hábito episcopal y acompañado de sus asistentes, también pequeñuelos, en memoria de la infancia del Salvador, ocupaba la silla del Prelado, los prebendados bajaban de sus asientos y eran sustituidos por los demás niños de coro, los cuales seguran representando al Cabildo en todo lo referente al culto del día, incluso en tomar a su cargo la dirección de los cantores y de la capilla de música.

Que esta fiestecilla escolar sea un tipo de representación lo acreditan los mejores estudiosos del teatro medieval (9).

A somewhat closer approach to the drama is made in one of the other celebrations of the Christmas season mentioned above: the revels of the choir-boys on Innocents' Day (Dec. 28), which appear to have been known as early as the tenth century. Just as in the Feast of Fools the subdeacons take control, so here the choir-boys assume the highest responsibilities, flout their elders, and introduce as much levity as the community will alow. In these activities they are led by a Boy Bishop, or Episcopus Puerorum, whom they elect well in advance of the feast, often on St Nicholas' Day (Dec. 6). The Boy Bishop flourished in every country of Western Europe, and especially in France and England...

Although the Feast of Fools and the custom of the Boy Bishop contain occasional features which can be identified as drama, it is scarcely necessary to insist that in their fundamental conception they are allied to sheer revelry and hilarity rather than to the stage.

No obstante, el general desconocimiento de lo español se manifiesta en uno de los más famosos y manejados:

I have no special records of the Boy Bishop in Spain except the council [Concilio 38 de Toledo, en 1587] (10).

Algún otro investigador que se acercó fructiferamente a nuestro país se manifiesta así (11).

The deacons were honored on December 26, the feast of St. Stephen, the priests on December 27, the feast of St. John, the choir boys, 
with their «bishop», on December 28 , Innocents Day, and the subdeacons on January I, or January 6. In Spain the boy-bishop and his antics were known at Toledo, Palencia, Zaragoza, Seville, Málaga, Salamanca, Lérida, Gerona, Vich, Mallorca, and many others places [Barcelona, Granada, Huesca, Perpiñán, Seo de Urgel].

Ya vemos que en España era frecuente la celebración, una particularidad más, algunas veces se celebraban otras fiestas:

En este día [de San Juan] a Vísperas se acostumbraban hacer una inocentada los muchachos; se hace uno Obispo, y otro Herodes [Huesca] (12).

A veces, como en Gerona, tenían incluso un rival: asf ocurría con el Albacillo de la Colegiata de San Félix.

La forma de celebrarse en Granada es una remodelación seria de lo que en general venía ocurriendo hacía ya siglos.

Al masificarse la enseñanza tanto en escuelas catedralicias como en colegios e incipientes universidades, la festividad que tenía un fin religioso, como aventura de la Rosa, sufrió una transformación laica y profana que dio lugar a numerosas prohibiciones; pero solo tomaré dos notas, una del S. XV:

Magnus et detestabiles abusus, qui per Regum Franciae in diversis fiunt Ecclesiis, et Abbatis Monacorum et Monialium, stultorum Festum (ut ipsi vocant) celebrando ubi abominabilis fiunt inordinationes et insolentiae, quae satis cognosci possunt absque hoc, in propriis descubantur nominibus, mala talia et abominabilia festa ex presse reprehendentes (13).

Si el Canciller de París, Gerson, vivio entre 1363-1429, tomemos ahora un texto español de nuestro siglo. Procede de uno de los más conspicuos y sabios discípulos de Menéndez Pelayo, don Adolfo Bonilla y San Martín (14).

Por razón de los escándalos que se originaban, escándalos que llegaban a su colmo con motivo de la «fête des fous» y del nombramiento del «episcopus puerorum», orgía carnavalesca en que los clérigos, disfrazados, hacían pantomimas, decían una misa burlesca en hábitos seglares, bailaban y cantaban en el coro descompuestamente, y se paseaban por la ciudad en carros, gritando bufonadas y obscenidades.

Como consecuencia de los escándalos, las prohibiciones; pero, cuando un verdadero «pastor ecclesie» se da cuenta de las inmensas posibilidades 
pastorales, lo transforma, como hemos visto, retrotrayéndolo a su prístina, mística y eclesial forma.

Pero recordemos que fray Hernando fue Arzobispo de Granada entre 1493 (en que recibe el palio) y 1507, en que muere; en consecuencia, esta forma «sería» de la celebración del Obispillo tiene que ser anterior a 1507, quizá... quizá en torno a 1500, cuando el Colegio de San Cecilio, especie de Seminario tal y como lo adoptará el Concilio de Trento, está funcionando a pleno rendimiento.

Por las noticias que nos han transmitido, las diócesis sufragáneas adoptaron el mismo sistema; he aquí un texto ilustrativo:

Las buenas y loables costumbres y cerimonias que se guardan en la Yglesia Cathedral de Guadix conforme a los que se guardan en la Santa Iglesia de Granada (15).

Esta noticia se refiere a la Dibcesis de Segovia, en la primera mitad del S. XVI.

La celebración del obispillo en la sede granatense durante el arzobispado de fray Hernando adquiere todas las connotaciones de una representación teatral, o para-teatral, litúrgica. Mientras la tensión religioso-mística se mantenga, estaremos dentro de la pedagogía de fray Hernando; pero cuando se rompa, entraremos en el mundo teatral escolar de antruejo, tipo Auto de Repelón.

Esto se extendió como podemos comprobar por otra noticia conocidísima del Concilio de Sevilla de 1512, que se produjo porque el año anterior de 1511, mientras se celebraba la fiesta, se derrumbo el cimborrio catedralicio sin que hubiera ninguna víctima (16).

*Nos D. Diego de Deza, Arzobispo de Sevilla, é el Dean, é Cabildo de la Santa Iglesia, deseando que perpetuamente se dén gracias á nuestro Señor y á su gloriosa Madre, especialmente por el beneficio en tal día recibido, é reformando en devoción lo que se hacía con alguna soltura de burlas, ordenamos 6 mandamos que de aquí en adelante el Obispo, é fiesta del obispillo que de antigua costumbre en esta Santa Iglesia, en memoria de la infancia $\epsilon$ humildad del nacimiento de nuestro Redendor Jesu-Christo, se hace é celebra el día de los Santos Inocentes, se haga con mucha honestidad $\epsilon$ devoción, predicando los memores á los mayores en la forma siguiente: conviene á saber: al canto de Magnificat, que se canta á las segundas vísperas de San Juan Evangelista, en llegando al verso Deposuit potentes de sede, los mozos de coro, y los clérigos de la Veintena se suban á las sillas altas y bajas 6 el Obispo se asiente en la silla del Prelado con sus asistentes, y los Beneficiados se asienten en las bancas bajas; después acabadas las vísperas 
vayan los Beneficiados que estaban vestidos de Presbíteros á la sacristia, y quitadas las capas de seda, tomen sus capas de panio, y tornen con el Pontifical del obispillo en orden cada uno con lo que el Dean ó Presidente le dixere; $t$ tráyanlo al coro: después de vestido el Obispillo comienzan las visperas de los Inocentes, y en tanto vaya el Obispillo á incensar el altar; tornado diga la oración, é eche su bendición; luego comience Completas, y un sacerdote de los de Veintena capitule y diga la oración, dende el Obispillo se vaya á desnudar á la sacristra.

Otrosi, cántense las horas de la Prima y Tercia muy bien, é uno de la Veintena diga la capitula $\epsilon$ oraciones, $\epsilon$ acabada la Tercia, se haga la procesión con sus capas de coro los Beneficiados, los quales vayan en el principio, comenzando el Deán y el Arcediano de Sevilla, yendo en orden todos delante, $\epsilon$ luego los Clérigos de la Veintena, $\epsilon$ tras de ellos los niños $\epsilon$ mozos de coro, y quatro mozos cantorcicos con sus capas de seda, $\varepsilon$ tras de ellos vaya el Presidente, $e$ diácono: en la cabecera ha de ir el obispillo con sus asistentes, $e$ tras de él dos beneficiados, el uno con la mitra y el otro con el báculo, $\epsilon$ un muchacho Beneficiado que lleva la falda al Obispo: el primer verso de la primera estación dicen los quatro cantorcicos con sus cetros: el segundo, quatro mozos de coro; el tercero, quatro Clérigos de la Veintena, han de tener el libro quando dicen el verso; quatro Beneficiados, dos que tienen los cetros é rigen la procesión.

Para esta procesión, porque se haga cada año perpétuamente en remembranza del martirio de estos Santos Mártires Inocentes, y por el beneficio en tal día recibido, dotó el reverendo Sr. D. Hernando de la Torre, Dean 6 Canónigo de esta Santa iglesia, como albacea y heredero del venerable Juan Gómez de Gamaza, Beneficiado y Vicario de Arcos, que haya gloria, dos mil maravedis, que se repartan de pitanza manual por los Beneficiados que fueren presentes, $\boldsymbol{\epsilon}$ interesante personaliter en esta procesión, demás de los dos mil maravedís que antiguamente se reparten por los Beneficiados en esta fiesta de los Inocentes de pitanza manual. Tornada la procesión al coro, el Obispo se vaya á su silla con sus asistentes, y los cantores comiencen el oficio de la Misa, é todos los Beneficiados la oficien. Al Obispo se le hacen ceremonias como á Beneficiado, trayendole el Evangelio, Epístola 6 incienso, paz, etc. Haya sermón de un buen predicador, y el Obispo y los mozos de coro se asienten en las bancas por su orden: acabada la misa, el Obispo dé su bendición, é luego uno de la Veintena comienza la Sexta, y quédanse alli siete ú ocho de la Veintena diciéndola: en tanto van todos los Beneficiados, acompañando al obispo fasta la capilla de San Christobbal, donde se desnuda; pero no han de ir en procesión, y el Beneficiado que no acompañare al obispo pierda la pitanza manual, excepto el Presbrtero, é Ministro que dixeron la Misa, porque se quedan desnudando en la sacristía. 
wtem, el Beneficiado á quien fuere encomendado algún servicio, sino sirviere cesante causa legítima, que demás de perder la pitanza manual, el Dean 6 Presidente le rape de los quadernos todas las horas de aquel día, y porque lo susodicho sea perpétuo, lo mandamos aquí asentar y firmar de dos canónigos, que fue fecho lunes día de San Juan Evangelista, veinte y siete días del mes de Diciembre, entrante el año del nacimiento de Nuestro Salvador Jesu-Christo de mil quinientos y trece años.»

Fray Diego de Deza era fraile dominico, Arzobispo de Sevilla e Inquisidor en 1506 cuando Rodríguez Lucero - Inquisidor de Córdoba-, Tenebrario según P. Mártir de Anghiera, procesa por judaizantes a los familiares de fray Hernando y aún intenta involucrarle a él mismo. No habłan sido amigos ni siquiera en la Junta de Madrid, cuando militan en bandos diferentes a los proyectos de Colón. Fray Diego no parece no digo admirar, sino ni respetar, el celo apostólico paulino de fray Hernando. Al menos, en vida; porque esta resolución de 1512 del Arzobispo Deza es una habilísima imitación de lo que había hecho el Arzobispo granatense. Fray Hernando, como El Cid, gana batallas después de muerto.

El ejemplo de fray Hernando fue como una piedra en una superficie líquida: se extendió en ondas concéntricas y así ocurrió que el Cardenal Tavera, toresano como Deza, toma esta otra decisión, respecto al Obispillo, pero ahora en Toledo y en 1538 (17).

«Don Juan Tauera por la diuina miseracion cardenal de la Santa yglesia de rroma de san juan ante portan latinam arçobispo de toledo primado de las españas chanciller mayor de castilla \&, juntamente con los rreverendos benerables nuestros amados hermanos el dean y cabildo de la nuestra santa yglesia dezimos que por quanto por parte de los dichos dean y cabildo fuimos avisados en dias pasados que en los oficios y fiestas que se acostumbran hazer en la dicha nuestra santa yglesia del obispillo que dizen de sant nicolas avia muchos excesos que se hazian ansi por los benefiçiados de la dicha nuestra santa yglesia que heran nonbrados por ofiçiales del dicho obispillo como por sus familiares y seruidores y otras personas que venfan en avitos yndeçentes a cuya causa avía mucha perturvacion y desasosiego en el oficio divino en los tales dias e ansi mismo los clerizones hazian muchas trauesuras y desverguencas ansi en el oficio de dia como de noche en los maytines lo qual por nos visto atento lo que sobre lo susodicho disponen los sacros canones y concilios generales y provinçiales y para quitar del todo la rraiz y ocasion de la turvación del culto divino y desonestidades y menospreçio de la dicha santa yglesia ques casa de dios y de ora- 
cion con acuerdo y paresçer de los dichos nuestros hermanos ovimos dado nuestra provision en que paresçer de los dichos nuestros hermanos ovimos dado nuestra provision en que en efecto se contenia que de oi en adelante cesare la election costumbre y çerimonia del obispillo en la dicha nuestra santa yglesia sobre lo qual despues Nos viniendo á esta çibdad, ovimos diversas vezes platicado con los dichos reverendos y benerables nuestros hermanos el dean y cabildo de la dicha nuestra santa yglesia y atento que la dicha election y çerimonia del obispillo se a hecho en ella de tiempo ynmemorial aca y en todas las otras de estos rreynos para exemplo de la umilldad y de la ynocencia que deve aver en los prelados y otras personas eclesiasticas y seglares y que no hera justo por los excesos de algunos particulares quitar del todo la dicha costumbre y serimonia tan antigua de la yglesia por no dar exempo (sic) a otras cosas mayores e atento que la dicha nuestra santa yglesia por tener el primado de las spañas es rrazon que sea exemplo de onestidad deçencia e yntegridad á todas las otras de españa ordenamos y estatuymos juntamente con los dichos nuestros hermanos que la election y oficio del dicho obispillo se haga y celebre agora y de aquf adelante con la onestidad y moderaçion siguiente primeramente que aviendo sigo elegido el obispillo uno de los clerizones de la dicha nuestra santa yglesia por votos de clavstro y clerizones en lescuela como se acostumbra hazer vayan el día de sant nicolas todos los benefiçiados que a la sazon rresidiesen al logar acostumbrado que es tras la puerta del perdon y estando los clerizones todos en vn tabernaculo cabo la capilla de nra. s." del estrella sin que aya sermon ni correo ni danças ni que echen monedas ni hayn desonestidad alguna e pidan los clerizones segun que acostumbran los votos e baxe la nuve con el angel y bonete del obispillo y hecho esto se vayan los beneficiados al coro con toda quietud y el obispillo se ponga en una silla alta de dignidades con dos asistentes clerizones y con su capa sirua en la dicha nuestra santa yglesia hasta el dia de los ynoçentes como se acostumbra y gane lo que suele como rracionero iten quel dia de los inoçentes no se rrepitan ofiçios algunos por los benefiçiados capellanes lectores ny clerizones de la dicha nuestra santa yglesia ni aya los tales oficios sino que el obispillo se asiente en la silla obispal y sus asistentes con el con tanto que no haga el oficio divino ni eche bendicion ni haga şerimonia alguna de prelado. Otrosí que qualquier beneficiado quel dia de sant nicolas o de los ynoçentes o otro qualquier dia durante el dicho obispillo hiziera algun desorden 6 desonestidad o se vistiere fuera del avito acostumbrado por el mesmo hecho yncurra en pena de dos meses de todo lo que podría ganar en la dicha nuestra santa yglesia los quales sean los meses de enero y hebrero durante los quales no pueda en ella entrar ni se le pueda rremytir el cabildo en parte ni en todo sin 
expreso consentimiento nuestro o de nuestros subcesores. Iten quel dicho dia de los ynoçentes ni otro alguno el obispillo no gouieme en el coro si no fuere el dean o presidente como se suele hazer yten que en la procesion del día de los ynogentes vaya en la cabeça el dicho obispillo con sus asistentes e luego las dignidades y canonigos y rracioneros con sus capas como se haze en otras procesiones otrosi ordenamos quel dicho obispillo y clerizones no salgan publicamente por las calles a caballo ni mula como lo hazían hasta aqui y si el dicho obispillo excediere en lo susodicho o parte dello pierda la procesion que a de aber del rrefitor y porquesta constituçion sea mejor guardada para agora y para sienpre jamas la mandamos asentar entre las otras constituciones de la dicha santa yglesia. E nos los dichos dean y cabildo ayuntados capitularmente llamados por çedula para lo susodicho lo otorgamos e juramos en forma de lo ansi tener y aguardar que fue fecho en la dicha çibdad de toledo dentro de la dicha nuestra santa yglesia a çinco del mes de dizienbre de mill e quinientes e treynta e ocho años.

A pesar de estas bienintencionadas reformas, en algunas escuelas, colegios o universidades provincianas siguió realizándose la elección del Obispillo y se alzaron, una y otra, voces contra la celebración. Al Concilio de 1565 se refieren algunos críticos, pero Bonilla San Martín nos indica este otro texto:

Antiguamente se solía usar muy ordinariamente en las iglesias, hazer un juego, que se llamaba de los Innocentes, o locos, en los días de San Nicolás, y de los Innocentes, en el cual porque se representaban cosas torpes, y se hazían otras cosas en offensa de Dios, en el concilio Basiliense se mando que en ninguna manera se hiziesse.

Y mucho antes deste Concilio en la octava del Synodo general se prohibi6 otro juego, que se parecfa algo a éste. Y se mand6 con graves censuras, se extirpase una costumbre, que tenían en algunos palacios de los Reyes, de componer en algunos días un lego con corona y las demás insignias de Obispo, y Patriarcha, para recrearse con esta representación, haziendo escarnio y burla del Obispo y Patriarca fingido. Despues del Concilio Basiliense, en un Concilio Provincial se mudo, que no se celebrase más este juego de los Innocentes.

Y en tiempo de Gerson, bachiller de París, se usaba, y por esto hizo un tratado, en el qual poniendo algunas conclusiones, reprehende la mala costumbre de hazer en las iglesias este juego de Innocentes, o locos, y prueba que es pecado mortal hazerle, y que pecan mortalmente los prelados que lo consienten. Eran tantas las deshonestidades, y cosas feas que se hazían en este juego, que justamente está vedado. Y aunque la ceremonia y representación que se hazía el día de Sant Nicolás de un nino con hábito episcopal, a quien traía una nube el bonete, en memoria 
de las antiguas electiones, que se hazían por inspiración del Spiritu Sancto, tuvo principio piadoso, pero no se debe permitir, porque parece que resulta della escamio, y vilipendio de la dignidad episcopal. Y porque los niños, y clerizones representándola toman occasión de hazer cosas indecentes, y deshonestas y offéndese Dios de que el pueblo, que se junta en los templos, vea cosas que provoquen a risas, y a los niños no les debe dar licencia para que se descompongan, haziendo esta representación y juegos...

En el Concilio Provincial que se celebró en esta ciudad de Toledo [1566] advirtiéndose los inconvenientes y offensas de Dios, que se seguían desta representación del obispillo, se mand6 [también en el Tarraconense del mismo año], que de allí adelante en ninguna manera se hiziesse. $Y$ por ser tan justo este decreto, es necesario se execute (18).

Todavía seguirán las reprobaciones: Toledo, 1587; Cádiz, 1591; y, a pesar de ello, Bermúdez de Pedraza dice lo siguiente en 1608 (19).

«La vigesima (iglesia parroquial) es la de San Nicolás Obispo, donde la universidad desta ciudad celebra su fiesta, y los estudiantes llevaban su obispo, vestido de pontifical; el qual tenía su silla junto al altar mayor, seguin vi en mi puericia: costumbre tan antigua desta ciudad, que tuvo principio de su primer Arçobispo don fray Fernando de Talabera: el qual acostumbraba, como en todas las demás yglesias $\mathrm{Ca}$ tedrales de aquel tiempo elegir de entre los moços de coro vn Obispo el día de San Nicolás, cuya dignidad duraua hasta el día de los Inocentes: en el qual mudándose los oficios de los mayores por los menores, mandando éstos, y obedeciendo aquellos; eran seruidos aquel día los que todo el año serufan. Pues como el santo Arçobispo era tan amigo de representaciones de humildad, tomaua Esta tan de veras como lo era antes que el demonio mezclase otras vanidades, que en estas cosas se hacen. Llegada, pues, la vigilia de S. Nicolás, venía el santo Perlado acompanado de su Deán y Cabildo, al de la yglesia donde estauan los colegiales del colegio Eclesiástico: proponia la elección que se aufa de hazer de Obispo, las calidades que aura de tener para ser buen Prelado, la razón de hazer esta fiesta, y los méritos de San Nicolás, a quien representaua. Encargaua la conciencia a sus capitulares, y conjuraua al Rector del colegio, para que pospuesto amor y odio, consultase qual de sus colegiales merecía aquella dignidad, no sólo por letras; pero por virtud; y hazía el escrutinio y diligencia para elegir vn Obispo de veinte días, como si fuera perpetuo; y tomados los votos elegía el que más tenía. Esta prelacía se estimaua en mucho: ansí por el fauor y buena reputación que cobraua como por el prouecho que tenfa; porque estaua ordenado, 
que para el vestuario y mesa capitular del obispo ganasse las distribuciones del coro, como uno de los racioneros con silla, después del vltimo. Llegado el día de los Inocentes lleuauan al Obispo desde su colegio al coro, vestido de pontifical, y acompañado de los demás oficiales: los quales con sus ropas y sobrepellizes representauan al nuevo Deán y Cabildo de la yglesia: y las Dignidades y Canónigos serúan de capellanes y criados del Obispo, y el santo Arçobispo de camarero, lleuando la falda con la humildad y modestia, que si el otro se la lleuara a é: lo qual se hazía con tal silencio y orden, como si el mesmo Arzobispo celebrara: el qual serufa en el coro, con tanto contento, quitando y poniendo los libros, boluiendo las hojas y guardando el verso junto al fascitor, en pie, y sin bonete, hablando con humildad y respecto con el nuevo Obispo y Cabildo, que no aura coraçón que no derramase muchas lágrimas de deuoción, deprendiendo a ser humilde. Esta costumbre sospecho que tuuo principio de la que tuvieron los Romanos de elegir y obedecer como a Rey en ciertas festividades a vno de sus criados, como refiere Macrobio en sus fiestas Saturnales».

Ya parece ser historia cuando Covarrubias, en el Tesoro de la lengua española (1611), voz «Obispillo», fol. 566v:

Antiguamente en las yglesias catedrales, en memoria de la santa elección que se hizo de San Nicolás, obispo de Myra, era un infante de coro que con solenidad, colocándole en medio de la yglesia en un cadahalso, baxava de lo alto de las bóvedas una nuve, y parando en medio del camino se abria. Quedavan unos ángeles que traían la mitra y baxavan hasta ponérsela en la cabeça, subiendo luego por la misma orden que avían venido. Esto vino a ser ocasión de algunas licencias, porque hasta el día de.los Inocentes tenía cierta jurisdición, y los prebendados tomavan oficios seglares, como alguaziles, porquerones, perreros y barrenderos. Esto, a Dios gracias, se ha quitado totalmente.

\section{Como historia lo vuelve a tratar Bermúdez de Pedraza en 1638 (20).}

Elegía de este colegio el día de San Nicolás, el Obispillo, costumbre antigua de las Catedrales. En llegando la víspera del santo venía a la Iglesia, juntaba su cabildo, llamaba al Rector, y proponía la elección, dezía la razón della, y los méritos de San Nicolás a quien representaba. Encargaba la conciencia al Retor, para que propusiesse al más digno, y a los capitulares que le nombrassen, haziendo el escrutinio que si fuera de sucessor suyo. Duraba este Obispo veinte días hasta el día de los Inocentes; y se estimaba en mucho, porque el obispo cobraba opinión, y favor con el Arçobispo: y era de provecho, porque 
tenía distribución y silla alta como Racionero, después del último de su Obispado, se trocaban los oficios. Los colegiales hazían los de Deán y Cabildo, y ellos el ministerio de los colegiales. Entraua el obispo vestido de pontifical en el coro, los colegiales sentados en el coro alto, y los capitulares en el coro bajo, y el Arçobispo en pie y sin bonete, servia junto al facistor de Sochantre, atendiendo al punto y verso. Y todo se hazía con el silencio y autoridad, que si celebrara de pontifical. Era muy amigo de las ceremonias de humildad, y oy se hazen en algunos colegios mayores. Y refiere Macrobio en sus Saturnales, como tuvieron origen de los Romanos, que en ciertas fiestas elegían, y reverenciauan a un esclavo por Rey. Y se conservó esta costumbre en esta Iglesia hasta veintiuno de Noviembre de mil y quinientos y veinticinco, en que la sede vacante eligio en su cabildo por Obispo a Francisco de Torres, colegial Vizaino, y en su pontificado hubo tales excessos, que obligo al año siguiente a derogar la costumbre el Cabildo, por auto de tres de Diziembre de mil y quinientos y veintiséis.

El tiempo no pasa en vano, una costumbre medieval de prístino valor enturbiado por malas costumbres, fue ensalzada a su esencia primitiva - como él quería también su iglesia - por fray Hernando de Talavera, retrocede a las corruptelas y va degenerando; la muestra definitiva ocurre en Sevilla (21).

«Conforme al estilo y por costumbre antigua, en el colegio de Maese Rodrigo, Universidad de Sevilla, los estudiantes hicieron su obispillo en la fiesta de S. Nicolas, su víspera el dra 5 de diciembre deste año de 1641. Salieron por las calles con el obispillo, que habia elegido, que fue un estudiante llamado D. Esteban Dongo, hijo de Bartolome Dongo, un hombre muy rico, genovés. En la puerta del colegio hicieron mucho ruido y alboroto con los que pasaban, haciendo apear a los coches a los caballeros, oidores y prebendados para que le besasen la mano á el obispillo, celebrándolo por chanza y fiesta del día. De all salieron por las calles con armas prohibidas, pistoletes, carabinas, trabucos y tercerolas, broqueles y estoques, llevando al obispillo en coche, haciendo mil bellaquerías $\epsilon$ insolencias en ellas y en las plazas con los pobres hombres y mujeres que vendían en ellas cosas de comer, pasando á quitar los coches, haciendo apear dellos a los jueces y ministros, disimulando assi esto como las quexas que les daban por esta causa, que solo sucede un día y en el permitidas estas licencias á los estudiantes.

Á la tarde vinieron al corral de comedias de la Montería, donde estaban ya representando quando llegaron y se entraron en los aposentos y hicieron volver á empezar la comedia con gran tolerancia del pueblo y de los caballeros y hombres honrados que la estaban oyendo 
y sufriendo lo que alborotaban. Al salir de allí quando les pareció, se arm6 una gran pendencia entre estudiantes y caballeros sobre querer quitar á uno dellos su coche y hubo con las cuchilladas algunos pistoletazos, de que salieron algunos heridos con riesgo de la vida. Los estudiantes hizieron cara, eran mas de sesenta, los caballeros no tantos. La Audiencia escribió la causa y el Teniente prendió á algunos estudiantes y el Acuerdo sacó una condenación grande á Bartolome Dongo, padre del obispillo (díxose que fueron quinientos 6 mil ducados) y por el Acuerdo se provey 6 auto, que notifico á el colegio, para que nunca hiciera obispillo y assf se ha observado hasta ahora.»

A partir de 1641 el Obispillo ha desaparecido; puede que se celebre en algún Monasterio, en cualquier pueblo arcaizante, pero ya sin la connotación religioso-místico-teatral, quedando, como es natural, en folclore, porque al perder la función sacral pervive en formas arcaicas de cultura popular.

\section{Bibliografia}

( 1) F. Hernando de Talavera: Obras, Ed., P. Mir, NBAE, T.16, pp. 19b y 12a.

( 2) Martinez De Toledo, A.: Libro del Arcipreste de Talavera, E.M. Penna. Parte II. Cap. IX, p. 115.

( 3) F. H. DE TAlavera: De cómo han de vivir las monjas, ms. a-IV-29 de la B. de El Escorial, fol. 12.

(4) Breve summa, cap. IX. He utilizado el ms 9545 de la B.N. de Madrid.

( 5) ROSA Y LÓPEZ, S. DE LA: Los seises de la catedral de Sevilla, Sevilla, 1904, cap. II, p. 46.

( 6) He manejado el ejemplar R-13474 de la Biblioteca Nacional de Madrid.

( 7) Caro Baroja, J.: El Carnaval, Madrid, Taurus, 1979, 3." parte, cap. III, p. 132, nota 21. [Pedraza, en 1638, se basa en Macrobio].

( 8) ROSA Y LOPEZ, S. DE LA: ob. cit., p. 46.

( 9) Young, K.: The Drama of the Medieval Church, Oxford, Clarendon Press, 1951, pp. $105-106$ y 110.

(10) Chambers, E.K.: The Medieval Stage, Oxford, $1967^{2}$, Libro II, cap. XV: $\ll$ The Boy Bishop», pp. 336-371. Esta nota está en la p. 350.

(11) Donovan, R.B.: The Liturgical Drama in Medieval Spain, Toronto, 1958, Cap. V, pp. 65-66 y 191-192.

(12) Ibidem, p. 191.

(13) Gersone, J.: Opera omnia, Antuerpiae, 1706, tomo III: «Quinque conclusiones super ludum stultorum», columna 309-310.

(14) Bonil LA SAn MARTtN, A.: Las Bacantes, o del origen del Teatro, Madrid, 1921, p. 73. 
(15) Donovan: ob. cit., cap. V, p. 59.

(16) SANChEZ ARJONA, J.: El teatro en Sevilla en los siglos XVI y XVII, Madrid, 1882, pp. 17-21.

(17) LoPez de Ayala y Álvarez de Toledo, J.: Toledo en el siglo XVI, Madrid, $1901, *$ Sobre una curiosa práctica de la Catedral de Toledo. El Obispillo de San Nicolás», pp. 163-165.

(18) Sandoval, Bernardino: Tratado del officio eclesiástico canónico, Toledo, 1568, Parte IV, cap. IX, pp. 117-118.

(19) Bermúdez De Pedraza, F.: Antiguiedad y excelencias de Granada, Madrid, 1608, Fols. 112v-113v. Citado por Caro Baroja.

(20) Bermúdez de Pedraza, F.: Historia eclesiástica, principios y progresos de la ciudad, y religión católica de Granada, Granada, 1638, fol. 99v.

(21) RosA LOPEZ, S. DE LA: ob. cit., p. 58. 